\title{
The discursive construction of resistance to sex in an online community
}

\begin{abstract}
This paper reports the analysis of a 26-million-word corpus of data from an online Pick-Up Artist (PUA) discussion forum. PUAs often use discussion forums as a place to share 'field reports' of their experiences in seducing and sleeping with women. Such online environments therefore provide a unique communicative space in which the notion of resistance to sex is discursively constructed and represented by forum members. Research in forensic linguistics has traditionally focused on the ways in which discourses of 'resistance' are used by police and lawyers to determine whether consent was given in cases of rape and sexual assault. This paper, therefore, provides an alternative perspective to this issue, and applies a corpus-assisted approach to discourse analysis in order to identify the ways in which 'resistance' is represented by this part of the PUA community. A collocation analysis of the community-specialist term 'LMR' ('Last Minute Resistance') finds three major themes emerging from the data: (i) resistance as something to be overcome, (ii) resistance as insincere, and (iii) resistance as remarkable. The paper ends with a discussion of the implications of these findings, namely in terms of counter-balancing the utmost resistance standard in the legal system and providing education to prevent the incitement of sexual aggression and cyber-enabled violent offences against women and girls.
\end{abstract}




\section{The discursive construction of resistance to sex in an online community}

\section{Introduction}

The notion of 'consent', and whether or not it was given, is often a source of dispute in criminal cases of rape and sexual assault. The prosecution narrative may be that consent was not given and that the victim was sexually assaulted or raped, while the defence counsel may attempt to create a narrative in which a complainant's behaviour could have reasonably been interpreted by their assailant as them giving consent. The discursive construction of consent holds such a privileged status in such cases because often the only evidence of whether consent was given is the testimonies of the people involved. The situation is made more complex given that people can consent without expressly stating 'I consent' (Tiersma, 2007: 91) and therefore the extent to which a person is consenting to something 'must be determined by inferences based on their speech and conduct' (Tiersma, 2007: 95). As Grant and Spaul (2015: 148) point out, the communication of consent may be non-verbal, and the 'interpretation of behavioural communication produces complications at law'. Such interpretations and inferences that people make about the behaviour of others are dependent on their beliefs about how people act or should act in specific situations' (Tiersma, 2007: 95). In particular, a question that is often directly or indirectly asked by a defence counsel is - did the alleged rape victim resist enough to prevent an assault or to communicate their dissent to their attacker? ${ }^{1}$ Writing on trials in Canadian courts, Ehrlich (2001: 67) emphasises that:

the 'utmost resistance standard' is the primary ideological frame through which the events in question and, in particular, the complainants' actions are understood and evaluated. This (re)framing functions to characterize the women as not 'resisting to the utmost' and ultimately (re)constructs the events as consensual sex, thus protecting the interests of the defendant.

The utmost resistance standard holds that if a woman did not resist a sexual attack to the utmost, then this is the same as giving consent. Although no longer a statutory requirement in the United States, this ideological standard of utmost resistance contributes to the 'revictimization that women can undergo once their complaints of rape enter the legal system' (Ehrlich, 2010: 265). For example, assumptions about utmost or 'appropriate' resistance have been found to infiltrate police interviews. In police questions, women are asked repeatedly

\footnotetext{
${ }^{1}$ Men can be, and are, victims of rape and sexual assault. This article focuses on cases where the victims are women.
} 
about their actions during an alleged sexual assault, and in their responses women anticipate an assumption by the police officer (or any future audience) that they might have been expected to take some 'other' and 'more' action in resisting an attack (MacLeod, 2010; 2016). By the time such cases get to trial, Ehrlich (2001: 92) demonstrates how the crossexamination of rape complainants is characterised by lawyers' questions which presuppose their behaviour to be lacking in appropriate resistance, framing the alleged victims as 'ineffectual agents' who 'consented' to sex by failing to resist (Ehrlich, 2001: 92).

Despite there being many reasons why a woman may not physically resist during a sexual assault (ranging from being physically paralysed with terror to being afraid of escalating violence), beliefs about whether a woman resisted enough are central in the discursive construction of consent in the legal system from interview through to trial. To date, forensic linguistic research has focused almost entirely on the relationship between 'resistance' and 'consent' within these legal parameters. This paper aims to examine this relationship in a discourse community outside of the legal system, but one in which the ideologies and ideals underpinning discussions of 'resistance' can bring a new perspective to this important social issue - the Pick-Up Artist (PUA) community, whose primary goal is to seduce and to have sex with women. Research into the PUA community has argued that the techniques that they advocate move 'from a seduction script, focused on conversation and comfort, to a more aggressive and coercive approach reflecting characteristics of rape scripts' (Denes, 2011: 418). Therefore, this paper aims to identify the way(s) in which 'resistance' is discursively constructed and represented within one part of the PUA community.

\section{The Pick-Up Artist Community}

Pick-up artists (PUAs) are a 'community of self-designated or aspiring seduction experts' (Dayter and Rüdiger, 2019: 13). Central to the PUA's seduction of women is a series of routines, techniques and 'scripts' that men are to follow to achieve sexual success with a woman. Such techniques are multifaceted and varied, but tend to be led by the three-stage model of human courtship as outlined by Erik von Markovic (also known as 'Mystery') in his book The Mystery Method: How to Get Beautiful Women into Bed (Mystery, 2007), the phases of which are now well-established within the PUA community: (i) Attraction, (ii) Comfort and Trust, (iii) Seduction. Some research has concluded that young men can enter the community motivated by self-reflection and self-improvement in response to expectations 
and cultural beliefs about masculinity, and community membership can have positive effects on self-esteem, perceived life-direction and emotional expressiveness and relationship building (e.g. Schuurmans and Monaghan, 2015). However, Denes (2011: 418) argues that PUAs, and in particular the brand of 'seduction' promoted by Mystery (2007), 'ultimately puts forth a script that condones the use and abuse of bodies and provides a problematic means of interpreting consent'. Not to say that all PUAs are rapists, of course, but in the popular media, PUAs and their practices are widely and regularly labelled as sexist and misogynistic (e.g. Bonnar, 2019; Hall, 2019; Bess, 2018). On occasion some high-profile PUAs make headline news, such as in 2014 when an American PUA was rejected a British visa to enter the country following a 150,000-signature strong online petition and amid accusations that he promotes sexual assault (Travis, 2014). The strongest critics of the PUA community can be so steadfast in their negative opinion of its underlying misogynistic ideology that the backlash targeted towards members can be vitriolic, to the extent that some high-profile PUAs have received rape and death threats online (Bender, 2017). While not attempting to 'exculpate the seduction community from criticism', O'Neill (2015: 10) challenges the cultural narrative in which the seduction community are considered 'pathetic, pathological or perverse - an army of sleazebags, saddos and weirdos', arguing that the PUA community is "not so much a deviation or departure from current social conventions as an extension and acceleration of existing cultural norms'. In her ethnographic research with the seduction industry and its members, O’Neill (2018) insists that the community should be taken seriously, rather than simply caricatured. In doing so, she makes the argument that the fundamental aspects which underlie the theory and methods of pickup or seduction, such as manipulation, the mechanical pursuit of orgasm, and any form of sexual coercion and sexual violence should be categorically rejected and refused (O'Neill, 2018: 152). Therefore, for the purposes of the present study, the ideologies, beliefs and discourses which underpin the PUA modus operandi for achieving sexual success with women provide an important space in which the notion of 'resistance' can be examined.

Most of the interaction between members of this community of practice now takes place online, with 'individual bloggers, dating coaches and relationship experts, all providing niche services and products on how to seduce women' (King, 2018: 300). However, much of the academic research in this area has focused on the online 'manosphere' more generallyof which the PUA community forms only part — and particularly the construction of masculinity in such spaces. For example, Ging (2019) examines masculinities in the PUA 
community along with sub-reddits, religiously conservative groups and men's rights websites. The 'manosphere', as Ging (2019: 638) characterises it, is a diverse assemblage of online networks and platforms 'generally united in their adherence to Red Pill "philosophy" which purports to liberate men from a life of feminist delusion'. ${ }^{2}$ Taking a more quantitative approach, Mountford (2018: 2) conducts a topic modelling procedure on just over 2 million words from Return of Kings $(R o K)$ a blog which aims 'to usher the return of masculine men' and found thirteen lexically derived topics emerging from the data. These topics include 'Goals and Growth', 'Pickup', 'Personal Relationships are Political', 'Prescriptive Society', 'Government and State' and 'Exercise'. Mountford (2018: 1) argues that these topics and groupings demonstrate the ways in which $R o K$ can be 'seen as prescribing a new form of masculinity that is consciously constructed in reaction to feminist and societal shifts'. Schmitz and Kazyak (2016: 1), meanwhile, analyse twelve prominent men's rights-affiliated websites and found two divergent ideological discourses which both 'promoted men's entitlement to social power'. On the one hand, some of the sites created hyper-masculine content that used themes of explicit aggression towards women and espousing the evils of feminism and reducing women to sexual commodities. On the other hand, some sites embraced a more socio-political stance to combatting perceived institutional misandry.

With regard to PUAs more specifically, Cosma and Gurevich (2018: 95) find that PUAs endorse a narrowly defined hegemonic masculinity while rejecting alternative masculinities, and that PUA leaders position themselves as 'authoritative voices' on selfimprovement in pursuit of this idealised masculinity. Shifting the focus away from masculine identity construction and towards the discourse of 'pick-up', Dayter and Rüdiger (2016) analyse the reconstruction of experience through narrative in a corpus of 37 posts from PUA forums, focusing on PUAs 'field reports', which are 'narrative constructions of encounters between the PUAs and women' (Dayter and Rüdiger, 2016: 337). Their analysis demonstrated how the field reports are used by posters to index and verify their membership in the community, and are underpinned by a frame of 'success' in which almost any outcome or response from women in the encounter is constructed as being successful and as the PUA achieving their goal. In later work, Dayter and Rüdiger (2019) explore in greater depth the nature and functions of PUA vocabulary, and particularly the ways in which features such as pseudoscientific terminology (particularly from the domains of military, business and

\footnotetext{
${ }^{2}$ Ging (2019: 640) describes the Red Pill philosophy as 'an analogy which derives from the 1999 film The Matrix, in which Neo is given the choice of taking one of the two pills. Taking the blue pill means switching off and living a life of delusion; taking the red pill means becoming enlightened to life's ugly truths'.
} 
science), statistics and quantification, abbreviations and acronyms and word-formation processes of compounding and conversion 'give the whole system a serious scientific air' and 'draw a border between those who are 'in-the-know' and those who are not' (Dayter and Rüdiger, 2019: 18). The present paper contributes to this growing academic interest in the online presence of the PUA community and discussion forums in particular. What is new here is the focus on the discursive construction of 'resistance' in the field reports posted by community members, a largely overlooked element of PUA discourse, and the implications of these representations more broadly.

\section{Methodology}

\subsection{The Seduction Forum Corpus}

The Seduction Forum Corpus (SFC) used in this analysis is a purpose-built specialised corpus comprising posts and threads from a popular and publicly accessible PUA online discussion forum. The posts to the forum are varied; some explicitly ask the community for seduction advice, some explicitly give such advice, and notwithstanding a series of posts about travel, fitness, entertainment and current affairs, the majority of posts are 'field reports' in which members provide narrative accounts of their encounters and experience with women. These reports are a tool for members to reflect 'on their interactions and discussing - often dialogically_ — what did or did not work for them' (Hambling-Jones and Merrison, 2012: 1116). The data were collected from the forum using GNU wget web-scraping scripts, and the posts and threads themselves were downloaded with all of their accompanying metadata. The dataset was pre-processed, which involved removing all of the web associated HTML tags and removing duplicate text in instances where a reply had 'quoted' chunks of the original or another post, and the files were stored as .txt and .json files. Following the pre-processing and data clean-up, the final corpus consists of 8,988 threads, comprising 25,788 individual posts and totalling 26,527,412 tokens, making the SFC the largest corpus of its kind.

There were ethical considerations that were borne in mind during the data collection and the subsequent presentation of the corpus here. At the time of data collection and writing, the forum from which the SFC is taken requires people to register in order to post messages in the forum but does not require registration to view posts; the forum is entirely accessible for the public to view online. Furthermore, one of the forum rules explicitly tells members to take 
steps to make sure that that they are completely anonymous, not using any names or contact information that could personally identify them or link them to another personal social media account. Therefore, given that posters to the forum have already taken steps to anonymise themselves and protect their privacy, it is clear that they expect their posts to be accessible to the public. Nevertheless, following Rüdiger and Dayter's (2017) recommendations for dealing with PUA online forums specifically, a series of steps have been taken to protect the identities of the forum posters and keep intrusion to an absolute minimum. The name of the forum itself will not be given, and the data will be referred to as the 'SFC', no usernames will be provided for posts, and any googlable verbatim quotes or extracts from the forum will not be presented. Such steps are intended to add an extra level of protection to forum posters; to borrow Page et al.'s (2014: 60) distinction, the object of this analysis is the text rather than the people. The aim here is not to reveal anyone's identity, nor to link them in any way to anti-social or potentially criminal activity. The focus here will remain squarely on the ways in which the notion of 'resistance' is discussed and constructed in the forum posts.

\subsection{Corpus-based discourse analysis}

Corpus linguistic methods afford the discourse analyst the ability to quantitatively examine far larger datasets than is possible using a purely qualitative approach. The type of corpus approach employed here relies on the fact that discourse analysis 'offers a highly structured set of resources for classifying and interpreting language features', the components of which are quantifiable (Marchi and Taylor, 2018: 2). A quantitative analysis can identify frequent linguistic patterns in the discourse of a 26-million-word dataset that are not reliably observable otherwise. These quantitative results and the patterns observed then serve as 'points of entry' (Baker, 2010: 133) into the data, whereby the scope of the analysis shifts from considering the dataset as a whole towards the close-reading and interpretation of samples of the data that are representative of the patterns found. Therefore, a corpus approach to discourse is not wholly objective by virtue of being quantitative; the eventual interpretations of data extracts are not replicable in the strictest sense. However, the process that has brought the analyst to them is systematic, transparent and reproducible (Marchi and Taylor, 2018: 7). Such an approach forces the analyst to account for all of the data in the corpus, rather than 'cherry-picking' examples from the data that confirm their existing 
hypotheses or assumptions and the importance and pervasiveness of which can be overemphasised without a broader view of the data.

The analysis in this study began by creating a wordlist of the SFC using Wordsmith Tools (Scott, 2016a), which is a straightforward list of every word in the corpus accompanied by its raw frequency. Given that the focus of this study is on the representation of 'resistance', this wordlist was then filtered to show words with the stem resist*. Using the wildcard in this way returned the frequencies for the word resist and inflectionally related forms (Table 1 below). A particularly salient community-specific acronym, LMR (which means last minute resistance), was identified and from that point the focus of the analysis became $L M R$. The next step was to identify its collocates, that is, the words with which $L M R$ co-occurs in the corpus (in this case within a horizon of five words to the left and five words to the right of it). Collocates contribute to the meaning of a word, and 'give information about the most frequent or salient ideas' associated with it (Gabrielatos and Baker, 2008: 10). There are many ways in which collocation can be measured statistically, and in this analysis the preferred measure is the cubed variant of the mutual information statistic $\left(\mathrm{MI}^{3}\right)$. The $\mathrm{MI}^{3}$ statistic calculates the strength of association between two words taking into consideration not just the frequency with which they occur together, but also how frequently each of the words is found in total (Scott, 2016b). This measure was considered preferable to frequency alone as it promotes lower-frequency but more exclusive associations which can benefit identifying discourses associated with a word, while curbing the low frequency bias associated with straightforward MI. Furthermore, $\mathrm{MI}^{3}$ avoids the sensitivity to corpus size and any calculation of significance scaled to a particular range of values associated with $\mathrm{t}$ scores and log-likelihood respectively (see Brezina et al., 2015; Gablasova et al., 2017).

The collocate list produced by Wordsmith Tools returned a total of 546 collocates, and the next stage of the method involved reducing this large volume of output to a manageable amount through two stages of 'narrowing and funnelling' (Egbert and Baker, 2016: 195). The first stage involved setting a cut-off to only include the top 100 ranking collocates in terms of $\mathrm{MI}^{3}$ score. All of the collocates within the top 100 had an $\mathrm{MI}^{3}$ score of over 13, which is stricter than the threshold scores used in other research (e.g. Brezina et al., 2015). The next step was to group collocates together in such a way as to identify semantic or grammatical patterns that would not otherwise emerge (e.g. Baker et al., 2013). Six categories emerged in this process, accounting for 47 of the 100 strongest collocates. However, these individual lexical items do not constitute discourses in themselves. Rather, they are traces of discourses 
present in the text (Baker, 2010: 123) which need to be examined in context. Therefore, this categorisation of collocates bridges the move from the quantitative element of corpus-based discourse analysis to the qualitative analysis of these collocates in use. In doing so, these six collocate categories gave rise to three major and recurring thematic discourses surrounding the use of LMR in the corpus. The final stage of the analysis is the selection of text extracts from the data which are representative of these three thematic patterns, and the qualitative interpretation of these extracts to provide insights into the discursive construction of $L M R$, and 'resistance' more generally, in the PUA forum.

\section{Analysis}

\section{1 'Last minute resistance' (LMR)}

Table 1 shows the frequency of resist* words in SFC which, taken together, only appear with a frequency of 82.78 per million words in the corpus as a whole. From these frequencies it is clear that explicit mentions of resistance appear to be relatively rare within the broader landscape of the forum, rather than dominating the threads (as a comparison, $\operatorname{girl}(s)$ has a frequency of 204,331 , or 7702.66 per million words). Nevertheless, a raw frequency of over two thousand provides enough instances in this corpus to warrant examination.

Table 1: Frequency of resist* in SFC (raw frequencies and normalised per million words)

\begin{tabular}{lrr}
\hline word & freq. & pmw \\
\hline RESISTANCE & 1,337 & 50.40 \\
RESIST & 444 & 16.74 \\
RESISTANT & 133 & 5.01 \\
RESISTED & 105 & 3.96 \\
RESISTING & 100 & 3.77 \\
RESISTS & 66 & 2.49 \\
RESISTANCES & 4 & 0.15 \\
RESISTIVE & 3 & 0.11 \\
RESISTANTS & 2 & 0.08 \\
RESISTIBLE & 1 & 0.04
\end{tabular}

Total $2,196 \quad 82.78$ 
A cursory examination of some examples from the data of resistance in use demonstrates how forum members discuss different levels of resistance they have experienced:

(1) She put up almost no resistance to the bang. I was fuckin her within minutes.

(2) She agreed and I went to her place. There was some resistance but I eventually sealed the deal.

(3) You need to think about taking her somewhere, get her tipsy or high and alone, and then hammer through any last minute resistance.

Extract (3) introduces us to the PUA term 'last minute resistance'. The phrase 'last minute resistance' appears 139 times in the SFC, accounting for only $10.4 \%$ of all instances of resistance. Its corresponding acronym 'LMR', however, occurs with a total frequency of 1,348 , making it ten times as frequent as the full phrase, and more frequent than the word resistance itself. It is unsurprising that the acronym is used more commonly than the full phrase; Dayter and Rüdiger (2019: 16) argue that the use of acronyms by the PUA community is an attempt to distance the layperson and the uninitiated in the same way as specialist terms and acronyms in academic and scientific discourses. In The Urban Dictionary, crowd-sourced online dictionary where entries and definitions are uploaded, suggested and voted for by internet users, the top definition among others for 'LMR' (in this context) is:

Acronym for Last Minute Resistance. This is when a woman puts up some form of resistance right before you successfully lay her because she starts having second thoughts about having sex.

(Urban Dictionary, 2018).

Similarly, the pick-up-artist website PUAMore (2016) defines LMR as when 'a girl will prevent a man from escalating beyond a certain point in the bedroom'. O'Neill (2018) identifies Last Minute Resistance as one of the most well-established and commonly referenced concepts in the community. It represents the belief that women only give the impression of resistance prior to having sex as a way to preserve their reputation, and is one of the most central tenets of seduction theory and practice 'because it epitomises the idea that the affective and relational dynamics that typically precipitate heterosexual sex can be wilfully produced by one party over another' (O’Neill, 2018: 98). Extract (3) shows this wilful production, as a forum member gives advice to 'hammer through' LMR if it is experienced, providing the first insight into how this particular community views and 
discusses women's resistance to sex. Given this, and its frequency in the corpus, the acronym LMR will be the focus of the analysis here.

Six semantic categories emerged from the top 100 collocates with the highest $\mathrm{MI}^{3}$ association with LMR, accounting for 49 collocates in total (Table 2). As can be seen, most of these collocates are lexical collocates, predominantly verbs (e.g. battle, break, plow, encounter) and adjectives (e.g. heavy, fierce, shit). However, function words comprise some of the categories, such as determiners (e.g. any, much, (a) lot,) and prepositions (e.g. after, past, through). From these six collocate categories, three overarching discourse themes emerge which will form the structure of the qualitative analysis that follows. These themes each relate to some ideological perspective on women's resistance to sex expressed by members of the forum and provide an insight into how resistance is understood and constructed within this corner of the PUA community. They are: (i) resistance as something to be overcome, (ii) resistance as insincere, and (iii) resistance as remarkable.

Table 2: L5-R5 collocates of LMR using $\mathrm{MI}^{3}$ (raw frequency of collocation in brackets)

\begin{tabular}{ll}
\hline Category & Collocate of 'LMR' \\
\hline tackling resistance & $\begin{array}{l}\text { battle (16), battled (3), battling (3), break (17), breaking (10), busting } \\
\text { (7), comfort (13), deal (23), defeating (4), overcome (32), overcoming } \\
\text { (20), past (20), plow (6), push (21), tactics (11), through (72) }\end{array}$ \\
high-resistance & $\begin{array}{l}\text { anti (9), crazy (13), extreme (12), fierce (5), heavy (26), hour(s) (23), lot } \\
\text { (33), massive (11), more (43), strong (15) }\end{array}$ \\
low-resistance & $\begin{array}{l}\text { any (38), bit (21), much (35), no (137), some (87), whatsoever (10), zero } \\
(34)\end{array}$ \\
fake resistance & asd (20), shit (36), tests (17) token (14) \\
experience & encounter(ed) (17), gave (26), getting (29), giving (30), got (50) \\
post-resistance & after (45), bang (42), sex (27)
\end{tabular}

\subsection{Resistance as something to be overcome}

The first discourse theme for discussion is one in which last minute resistance from women and girls is represented by forum members as something that is to be defeated, battled or overcome by men. This theme is most plainly represented by the collocates in the 'tackling 
resistance' category in Table 2. Some field reports by forum members detail the ways in which they experienced $L M R$ from their targets, but persevered nonetheless:

(4) She drove almost an hour to come over tonight, I had to push through alot of LMR she kept saying no sex but that didn't stop me.

(5) We leave to a high-class hotel in town and after going up to our room she puts on a robe and we get at it. Have some LMR but plow through and fuck the shit out of her.

(6) But I had to put up with her shitty screaming and get past LMR. The sex was poor.

(7) Gave me a load of LMR but I pushed through. But she gave the worst blowjob I've ever had. She used too much teeth and I had to hit her on the head and give her directions.

In these examples, the forum members recount experiences in which they report 'plowing' and 'pushing' through resistance by the woman which, according to these reports, is manifest in 'she kept saying no' and 'shitty screaming'. Furthermore, in both (6) and (7) the forum posters negatively evaluate the sexual activity after having been made to 'get past' or 'deal with' LMR, while in (7) there is also an expression of physical violence in 'hit her on the head'. This suggests that even if a woman does eventually engage in sexual activity, they are met with degradation and physical abuse for initially resisting. The notion of a woman's resistance to sexual activity as being something to be overcome is most explicitly signalled by the collocate overcome/overcoming itself:

(8) I knew we were interested in each other when we first met. There was a lot of LMR but that was easily overcome by repeated efforts, logic or bulldozing.

(9) How forceful is everyone when trying to overcome LMR? Is it just on a case by case basis? Last week I had a date and the girl came back to my place and she ended up leaving in a huff because I let my hand wander after she had already said we weren't having sex. [...] I need to get better at dealing with this silliness.

Framing LMR as something to be overcome represents such resistance as a problem and an adversarial enemy, and in turn demonstrates the community's views of women's sexual resistance. The solutions to such a problem are expressed in (8) in terms of 'repeated efforts' and 'bulldozing' which align with the perseverance and pressure discussed in the examples above of 'plowing' and 'pushing' through LMR. In (9) the forum member is requesting advice from the community about overcoming LMR. Notably, their question is how 'forceful' to be when trying to have sex with someone who is resisting, indicating that force 
is an inherent factor in overcoming LMR. The same post makes the dehumanising reference to (sexual) encounters with women as 'cases', which reflects the misogynistic ideologies underlying many of these posts. In addition, there is further evaluation of the LMR reported in (9) which provides an insight into the community's views on sexual resistance. The user recounts a situation in which he attempted to overcome LMR and the girl left 'in a huff', before ending the post by lamenting the 'silliness', as they see it, of LMR. Such descriptions of resistance frame it as being childish and trivial, which serves to diminish and delegitimise the resistive actions of women.

Further contributing to the community's construction of resistance from a position of adversarial opposition are posters accounts of battling and defeating LMR using tactics:

(10) I get annoyed every time I see LMR. If I win the battle, I'll still be annoyed because she tried to reject me, but if I lose the battle, I'll be annoyed because I lost. So I always push through LMR as far as possible, unless she leaves.

(11) Once you got them back to your place, it's about escalating and defeating LMR.

(12) She gave some token resistance but also its also a cultural thing. Was no match for my LMR busting tactics.

All three of these LMR collocates draw on military and war metaphor, representing the pursuit of sexual satisfaction as a fight with winners and losers. This is clearest in (10) and (11) in which LMR is 'battle(d)' and 'defeated' respectively. Dayter and Rüdiger (2019: 15) argue that this type of military-related metaphor is appealing to PUAs as it implies that being 'a real man' is found in attributes 'such as power, physical strength and grit'. In the same way, the use of 'tactics' in (12) represents the man's actions as carefully planned, strategic and methodical, and imbues them with some sort of intellectual currency. By describing their persistence with sexual advances in the face of clear resistance from a woman in this way allows the forum posters to portray themselves as having positive physical and cerebral qualities rather than predatory, aggressive alternatives.

These posts detail instances where a man has ignored a woman's resistance to their sexual advances and have engaged in sexual activity. These posters were not only clear on the lack of consent shown by their targets, but are proud and boastful that they were able to persevere anyway. Within their ideological framework, their status as an alpha-male, a successful proponent of PUA 'methods' and as a victor on the sexual battlefield depends on 
their willingness and ability to overcome women's resistance. As a result, as Cosma and Gurevich (2018: 95) argue, within the PUA community 'sex with women is framed as an obstacle one must "work through" to become the true, ideal self'. The ways in which some members of the PUA community appear to morally legitimise their behaviour involve recasting the sexual encounter as another type of activity entirely through the use of military metaphor, by dehumanising women and referring to them as 'cases', and to downplay and trivialise a woman's resistance as childish and silly.

\subsection{Resistance as insincere}

In line with the argument that members of the forum trivialise women's resistance, another major discourse surrounding LMR as revealed by the collocate analysis is the representation of women's resistance as being fake, inauthentic and insincere (Table 2). The main way in which this is performed is through the description of the resistance as being token:

(13) On our first date I took her back to my place, got her in bed and she even gave me token LMR as if we were still teenagers, which was nice.

(14) And I would think it through and decide if she was having doubts that it would be wrong for something to happen. When in reality it was the most token of LMR probably more frustration that I hadn't taken off her panties yet.

(15) I gave her many orgasms, and I know pushing through her token LMR really turned her on.

Token is used here in such a way that indicates that the LMR expressed by the women in question is symbolic and performed for the sake of appearances, particularly to avoid appearing promiscuous. In the seduction community and beyond, 'token resistance' is when a 'woman says no to sex even when they mean yes' (Muehlenhard and Hollabaugh, 1988: $872)^{3}$, and is problematic given that viewing resistance in such a way makes it 'difficult to envisage any situation in which a woman's "no" would legitimately be heard as such (O’Neill, 2018: 101). The examples of token LMR in (13)-(15) reveal a lot about how the PUA community within SFC view such resistance. In the simplest terms, this resistance is not

\footnotetext{
3 Research into 'token' resistance has found that women do sometimes say 'no' when they want to have sex (e.g. Muehlenhard and Hollabaugh, 1988; Shotland and Hunter, 1995). However, such studies consistently find that it is a substantial minority of women who do so for deceptive or manipulative reasons (such as increasing their partner's arousal by making him wait). Rather, what is perceived as 'token' resistance by women in these studies is more often a result of emotional, religious or moral concerns, the inappropriateness of the situation at the time, a fear of appearing promiscuous, or because they genuinely changed their sexual intentions during a date or encounter.
} 
believed or taken seriously. In (13), non-genuine 'token' resistance is associated with juvenility and sexual immaturity on the part of the woman whose expression of resistance is considered the behaviour of a 'teenager'. In (14), not only is the resistance not considered genuine, it is framed by the poster as signalling the exact opposite of resistance; he reports that it is likely that what the woman was really trying to communicate was that she could not resist any longer and could not wait for him to take off her underwear. A similar recasting of LMR is seen in (15). Here, the forum member is certain that 'pushing through' the woman's 'token' LMR, rather than being a cause for concern for the woman and her safety, was in fact the source of sexual arousal for her.

A related community-specific term is 'ASD' (Anti-Slut Defence). ASD is a another well-established concept in the community and is defined as a women's 'internal mechanism to create plausible deniability before sex with a new man. It ensures that she doesn't appear (to herself and others) that she's too easily seduced' (PUA Lingo, 2018a). Appropriately, discourses of LMR and ASD overlap in the SFC, as the latter is a common collocate of the former (Table 2):

(16) I encountered levels of ASD and LMR that were not apparent on the first date - I'm still fairly new to this, and my poor attempts to overcome the unexpected LMR backfired.

(17) It takes game to disable ASD and LMR after you get her back to your place

(18) You could have (should have) fucked her on that first date. She was asking for it she just needed you to plow through her very weak LMR/ASD.

In these examples, a woman's resistance to sexual activity is considered a manifestation of her ASD. Rather genuinely expressing resistance and lack of consent to sex, these women actually $d o$ want to have sex, but are only showing resistance so as to not appear a 'slut' to themselves or anyone else. In the same way as describing LMR as 'token', representing resistance as an insincere self-protective measure used by women to save their own reputation rather than an actual lack of consent serves to diminish the legitimacy of the resistance and in turn makes it an easier moral decision for men to continue with sexual advances; women really do want to have sex, regardless of what they say or do.

Like ASD and token LMR, shit tests is a community-based register-specific 'technical' term, defined as 'often unconscious (and sometimes conscious) tests that women 
throw at men in order to quickly determine their social status' and occur 'when a woman gives a guy a hard time, usually for the purpose of seeing how he will react' (Pua Lingo, 2018b). Shit tests of this kind are bundled together in collocation with LMR in various ways in SFC:

(19) SO much LMR. She said she wasn't ready like 10 times, I but I plowed through that. The language reminded me of some of the LMR and shit-tests I've heard here. It was funny.

(20) 15 minutes later we were making out - but every time I reached for her pussy I got heavy LMR, shit testing me all evening

(21) What's a good response for when she says 'but it's the first date' type of LMR? I failed that shit test but the prospect of a second date prospect is strong.

Framing LMR together with shit tests creates the sense of competition between the men and women in pick-up encounters. It implies that resistance is a 'test' that the woman is setting for the man, and he will either pass or 'fail' (as in 21) depending on whether or not they end up having sex. This way, much like token LMR, shit tests are framed as deceptive and manipulative strategies used by women to counteract the seduction strategies employed by men. Considering resistance in this way, and repositioning the event as a challenge, recontextualises the sexual activity and ultimately makes it easier for men to ignore resistance. For the PUA, passing a shit-test and/or overcoming LMR is an alpha-status-affirming victory rather than an act of sexual violence.

The ideological assumption that LMR is 'token' resistance, the product of some selfprotective anti-slut defence or a deceptive shit test set by women to challenge men may 'encourage men to ignore women's refusals' and strengthen a man's belief that 'women's refusals are not to be taken seriously' (Muehlenhard and Hollabaugh, 1988: 878). Indeed, accounts by convicted rapists of their crimes demonstrate the ways in which their (mis)understanding of consent is based on notions of token resistance - their victims said no but they didn't mean it (Scully and Marolla, 1984: 534; Pemberton, 2012: 130). The posts analysed here show how resistance, and LMR in particular, is discussed within ideological frames of 'anti-slut defence', 'shit-tests' and 'token resistance'. By consistently being associated with deceit and attempts to mislead, LMR 'licenses men to disregard what women say' and instead men believe that 'they are in fact fulfilling women's unspoken and 
unspeakable desires' (O’Neill, 2018: 101). In turn, this undermining of the legitimacy and sincerity of a women's resistance, demonstrates and exemplifies Denes’ (2011: 417) warning that the PUA community 'may be perpetuating false beliefs about the prevalence of token resistance and inadvertently contributing to sexual aggression'.

\subsection{Resistance as remarkable}

As has been demonstrated, PUAs are persistent and insistent in the face of repeated and explicit signals of resistance. The third theme surrounding LMR emerging from the collocates in Table 2, which relates particularly to collocates in the 'High resistance' category, is the ways in which LMR is represented in instances when they are not able to overcome it:

(22) Pulled a girl in a club last night, but couldn't overcome heavy LMR. Not usually an obstacle for me.

(23) The last few times I did this it resulted in two lays and 1 heavy make out. Could've easily been all three if not for a strange case of strong LMR.

(24) Got a second date with a girl but got severe LMR and never got the bang. So this seems a bit unusual.

(25) My last 3 pulls have all put up massive LMR. I only banged one of them and that was after a whole night of trying [...] normally I consider pushing through LMR to be a strength of mine, so I'm a bit confused and attempting to diagnose the problem.

In these instances, the LMR reported by forum members is heavy, massive, strong and severe. When PUAs are forced to post field reports of encounters where they were not successful in escalating to sex, the steadfastness of the woman's resistance is emphasised by these evaluative adjectives as being remarkable or unusual. Moreover, such instances are described as 'strange' (23), 'unusual' (24) and are a source of confusion (25). A woman's resistance to the sexual advances of man can only be considered strange, unusual or confusing when viewed from an ideological perspective characterised by patriarchal beliefs related to male sexual entitlement and female sexual compliance. The brand of masculinity which underlies 'The Red Pill' philosophy and online spaces such as those occupied by PUAs is 'orientated to achieve the traditional hegemonic aims of sexual conquest, social dominance, and selfimprovement using misogynistic philosophy' (Mountford, 2018: 2). Such an ideology is 
situated within a wider patriarchal world-view in which 'men have strong, and often uncontrollable, sexual needs that must be fulfilled and that women must serve that purpose' (Bouffard, 2010: 871). Therefore, when individuals with such a perspective encounter resistance to the extent where they do not eventually have sex, their reaction is one of confusion that such resistance could be unusually and puzzlingly high. Such is the unexpectedness of effective resistance from women that it is framed as a 'problem' which needs to be 'diagnosed' (25). Indeed, there is further evidence of forum members trying to account for the extreme or severe LMR that they counter:

(26) She invited me to her place and I though I was going to get the bang but she put up extreme LMR both times. My analysis is the same as yours: she was recently a "victim" of a pump and dump and is trying to get a man to sign up to a relationship before putting out

(27) There's also the advantage that if she turns out to be looney or starts giving you severe LMR then you're free to walk away without having to worry about how you're going to get this weird chick to move out.

Here, the commenters resolve that there must be something wrong with the women in question that explains the amount of resistance that they put up. Rather than being a legitimate lack of consent to sex, the women must either be reeling from a recent bad relationship (26) or are 'loony' and 'weird' (27). When the patriarchal ideals underlying the PUA ideology hold the traditional sexual script 'in which women's role is to act resistant to sex and men's role is to persist in their sexual advances despite women's resistance' (Muehlenhard and Hollabaugh, 1988: 872), there needs to be some explanation when this does not come to pass. To put it another way, there must be something unusual at play when a woman's resistance to sex is revealed to be genuine, rather than 'token'. As is demonstrated by these examples, this is regarded as being the fault of the woman, again serving to diminish women's agency in consensual sex.

Posts in the corpus also show that forum members weigh-up the trade-off between overcoming unusually high levels of LMR and their subsequent levels of satisfaction:

(28) I got a girl to my place and we kissed but the bitch was teasing me with crazy LMR and saying she don't have sex without love. She wasn't hot enough to be worth it so I kicked her out. 
(29) The date is usually boring, conversation is shit, no passion, heavy LMR, and even if do you have sex with her the sex sucks. Then you ask yourself, was that even worth it? to go through all of that.

(30) Today I had a date with tall girl but she gave me crazy LMR. I could barely get her top off but no change with the pants. I pulled my dick out and she gave me a rubbish handjob. I also noticed her freakishly large feet.

In (28) the poster determined that the woman in question was not worth battling 'crazy' LMR so kicked her out. However, as (29) and (30) show, even if they do have sex the men are resentful of the initial resistance and insult the woman or her sexual performance. Research into sexual coercion (e.g. Baumeister et al., 2002; Bouffard, 2010) has argued that some men may interpret a woman's resistance to their sexual advances as a personal insult and a denial of their freedom and entitlement to gain sexual gratification and therefore they may react angrily. 'The sex sucked' in (29) and 'freakishly large feet in (30) show that one manifestation of this anger in these posts seems to be to degrade and demean any woman who has the audacity to show them resistance, regardless of whether or not they eventually succumbed to the man's advances.

\section{Implications}

This paper has reported the findings of a corpus-based discourse analysis of an online pick-up artist forum. In particular, it has used a collocation analysis of the community-specific term 'LMR' (meaning 'last minute resistance') to identify the ways in which women's resistance to sex is discussed and represented by community members. The three main discourse themes emerging from the analysis show resistance as being something to be overcome, battled and pushed through. It has been argued that in order to justify or rationalise such behaviour, sexual encounters are represented as competitions or challenges, with positive physical and mental attributes associated with those men who are victorious. At the same time, women's resistance to sex is trivialised, disbelieved or ignored entirely, most often by considering all resistance to be token, or part of a woman's anti-slut defence or shit testing. In instances where PUAs are unsuccessful in having sex with a woman, this is considered unusual, and accounted for by the assumption that there must be something wrong with the woman.

The aim of this paper is not to claim that all members of the pick-up artist community are rapists, or to simply criticise the actions and communication of this particular group or 
PUAs generally; such criticism in this context 'does little to help advance our understandings' of the social, cultural and discursive phenomenon of the PUA community (King, 2018: 303). Rather, the possible implications of the discourses revealed here should be discussed, and two such implications will be presented here. First, the findings of this analysis can be triangulated with those of studies in forensic linguistics and provide new insights into the relationship between resistance and consent. Ehrlich (2001) and others have demonstrated the ways in which complainants of rape and sexual assault in the West are held to the utmost resistance standard. What has been shown in the extracts from the data here is that women can face utmost persistence from men, despite the amount and nature of resistance they express. Although the PUA community does not represent all men, providing this alternative view can provide a counter-balance to the utmost resistance standard and help alleviate the victim-blaming assumptions that can underlie cases of rape and sexual assault. This in turn could accelerate a societal shift to a position in which the persistence women are faced with is better understood. Doing so may remove one of the biggest barriers to victims reporting sexual assault or rape - the fear that they will not be believed.

Second, online discussion forums are places where like-minded people with similar values and norms seek each other out to collectively reinforce their beliefs and rationalise their actions, particularly when the ideologies they share are widely stigmatised by 'outsiders' (Bloch, 2016: 265). In a PUA context, ideologies are not only affirmed but are celebrated, as members are vying for each other's approval in a quest to achieve the ideologically constructed hyper-masculine alpha-male identity so revered in the community (Schuurmans and Monoghan, 2015). By extension, there is evidence to suggest that within these forums, advice from like-minded people can affect forum members' offline behaviour (e.g. Sillence, 2010). More specifically, recent research has found that individuals who hold problematic beliefs about sex, such as a perspective that sex is a game in which men must emerge victorious, are especially likely to use the kinds of techniques promoted by the PUA community to manipulate potential sexual partners (Klement et al., 2019). Therefore, in a situation in which potentially dangerous ideologies about women's resistance to sex are being shared and reinforced, and tales of sexual victory after pushing through or overcoming sexual resistance are proudly told, this may increase the risk of forum members committing violent sexual crimes offline. In which case, such discussion spaces become the source of cyberenabled violence against women and girls, and some of the posts that have been presented here may constitute incitement of such violence. A knowledge of the sorts of ideologies that 
are being shared online can help tackle them. Rather than policing online spaces, young men and women could be educated about these myths surrounding resistance so that if (or when) they do encounter them online, they do so with a healthy understanding of sex, consent and resistance.

\section{Acknowledgements}

I express my enormous gratitude to Ikechukwu Onyenwe for his work on collecting and preparing the corpus for analysis. I also thank the anonymous reviewers for their very helpful comments on earlier drafts of this work. This research is funded by a British Academy/ Leverhulme Small Research Grant - (grant reference: SG162829).

\section{References}

Baker, P. (2010). Sociolinguistics and Corpus Linguistics. Edinburgh: Edinburgh University Press.

Baker, P, Gabrielatos, C and McEnery, T. (2013). Sketching Muslims: a corpus driven analysis of representations around the word 'muslim' in the British Press 1998-2009. Applied Linguistics 34(3): 255-278. https://doi.org/10.1093/applin/ams048

Baumeister, R. F., Catanese, K. R., and Wallace, H. M. (2002). Conquest by force: a narcissistic reactance theory of rape and sexual coercion. Review of General Psychology 6(1): 92-135. https://doi.org/10.1037\%2F1089-2680.6.1.92

Bender, S.M. (2017). 'Happy to provide the knives': governmentality and threats of violence via social media in the case of Roosh V and Return of Kings. First Monday 22(3) http://doi.org/10.5210/fm.v22i3.6945.

Bess, G. (2018). What it's like to be hit on by a pick-up artist. Vice. (Online). 19 January 2018. [Accessed April 2020]. Available from: https://www.vice.com/en_us/article/bjy3q4/playing-the-game-the-game-a-hauntingpick-up-artist-dating-sim-angela-washko.

Bloch, K.R. (2016). "It is just SICKENING": emotions and discourse in an anti-immigrant discussion forum. Sociological Focus 49(4): 257-70. https://doi.org/10.1080/00380237.2016.1169901

Bonnar, M. (2019). The seduction game. BBC (Online). 7 October 2019. [Accessed April 2020]. Available from: https://www.bbc.co.uk/news/extra/tmZeuc7TX0/theseduction-game. 
Bouffard, L. A. (2010). Exploring the utility of entitlement in understanding sexual aggression. Journal of Criminal Justice 38(5): 870-879.

https://doi.org/10.1016/j.jcrimjus.2010.06.002

Brezina, V., McEnery, T. \& Wattam, S. (2015). Collocations in context: a new perspective on collocation networks. International Journal of Corpus Linguistics 20(2): 139-173. https://doi.org/10.1075/ijcl.20.2.01bre

Cosma, S. and Gurevich, M. (2018). (Re)producing the 'natural man' in men's online advice media: achieving masculinity through embodied and mental mastery. Psychology \& Sexuality 9(1): 86-97. https://doi.org/10.1080/19419899.2018.1434230.

Dayter, D. and Rüdiger, S. (2016). Reporting from the field: the narrative reconstruction of experience in pick-up artist online communities. Open Linguistics 2(1): 337-351. https://doi.org/10.1515/opli-2016-0016.

Dayter, D. and Rüdiger, S. (2019). In other words: ‘the language of attraction’ used by pickup artists. English Today 35(2): 13-19. https://doi.org/10.1017/S026607841800007X.

Denes, A. (2011). Biology as consent: problematizing the scientific approach to seducing women's bodies. Women's Studies International Forum 34(5): 411-419. https://doi.org/10.1016/j.wsif.2011.05.002.

Egbert, J. and Baker, P. (2016). Research synthesis. In: P. Baker and J. Egbert (eds.), Triangulating Methodological Approaches in Corpus-Linguistic Research. London: Routledge, pp. 183-208.

Ehrlich, S. (2001). Representing Rape: Language and Consensual Sex. London: Routledge.

Ehrlich, S. (2010). Rape victims in the legal system. In: M. Coulthard and A. Johnson (eds.), The Routledge Handbook of Forensic Linguistics. London: Routledge, pp. 265-280.

Gablasova, D., Brezina, V. \& McEnery, T. (2017). Collocations in corpus-based language learning research: identifying, comparing and interpreting the evidence. Language Learning 67 (Suppl. 1): 155-179. https://doi.org/10.1111/lang.12225

Gabrielatos, C. and P. Baker. (2008). Fleeing, sneaking, flooding: a corpus analysis of discursive constructions of refugees and asylum seekers in the UK Press 1996-2005. Journal of English Linguistics 36(1): 5-38.

Ging, D. (2019) Alphas, Betas, and Incels: theorizing the masculinities of the Manosphere. Men and Masculinities 22(4): 638-657. 
Grant, T. and Spaul, K. (2015). Felicitous consent. In: L. Solan, J. Ainsworth and R. Shuy (eds.), Speaking of Language and Law: Conversations on the Work of Peter Tiersma. Oxford: Oxford University Press, pp. 145-149.

Hall, H. (2019). Sleazy pick-up artists are thriving - and they're exploiting men's insecurities over \#MeToo to do it. The Independent (Online). 8 October 2019. [Accessed April 2020]. Available from: https://www.independent.co.uk/voices/seduction-boot-camppanorama-pick-up-artists-metoo-misogyny-a9148041.html.

Hambling-Jones, O., and Merrison, A. J. (2012). Inequity in the pursuit of intimacy: An analysis of British pick-up artist interactions. Journal of Pragmatics 44: 1115- 1127. https://doi.org/10.1016/j.pragma.2012.04.008

King, A. S. (2018). Feminism's flip side: a cultural history of the pickup artist. Sexuality \& Culture 22(1): 299-315. https://doi.org/10.1007/s12119-017-9468-0.

Klement, K. R., Xoxakos, P., Nazario, M., Erickson, J. M., Salley, S., Pieterick, M., DeLaFuente, J. L., Hemmerling, T. R., Martin, K. and Sagarin, B. J. (2019). Winning the game: how sexual narcissism relates to adversarial sexual beliefs and pick-up techniques. Sexuality \& Culture 23(4): 1283-1300.

MacLeod, N. (2010). Police Interviews with Women Reporting Rape: A Critical Discourse Analysis. PhD thesis, Aston University. Available from: https://research.aston.ac.uk/en/studentTheses/police-interviews-with-womenreporting-rape-a-critical-discourse-

MacLeod, N. (2016). 'I thought I'd be safe there': Pre-empting blame in the talk of women reporting rape. Journal of Pragmatics 96: 96-109. https://doi.org/10.1016/j.pragma.2016.03.008.

Marchi, A. and Taylor, C. (2018). Introduction: partiality \& reflexivity. In C. Taylor and A. Marchi (eds.), Corpus Approaches to Discourse: A Critical Review. London: Routledge, pp. 1-16.

Mountford, J. B. (2018). Topic modelling The Red Pill. Social Sciences 7(3) (Online). Available from: https://doi:10.3390/socsci7030042.

Muehlenhard, C. L. and Hollabaugh, L. C. (1988). Do women sometimes say no when they mean yes? The prevalence and correlates of women's token resistance to sex. Journal of Personality and Social Psychology 54(5): 872-879.

Mystery. (2007). The Mystery Method: How to Get Beautiful Women into Bed. New York: St. Martin's Press. 
O’Neill, R. (2015). The work of seduction: Intimacy and subjectivity in the London 'seduction community'. Sociological Research Online, 20(4). https://doi.org/10.5153\%2Fsro.3744.

O’Neill, R. (2018). Seduction - Men, Masculinity and Mediated Intimacy. Cambridge/ Medford: Polity.

Page, R., Barton, D., Unger, J. and Zappavigna, M. (2014). Researching the Language of Social Media. London: Routledge.

Pemberton, S. L. (2012). Talking about rape: a discursive study of convicted adult rapists' accounts of rape. $\mathrm{PhD}$ thesis, Nottingham Trent University. Available from: http://irep.ntu.ac.uk/id/eprint/19/.

PUALingo. (2018a). 'Anti-Slut defence'. https://www.pualingo.com/anti-slut-defense/ PUALingo. (2018b). 'Shit test'. https://www.pualingo.com/shit-test/

PUAMore. (2016). 'Last Minute Resistance'. https://puamore.com/wiki/lmr-last-minuteresistance/.

Rüdiger, S. and Dayter, D. (2017). The ethics of researching unlikeable subjects: language in an online community. Applied Linguistics Review 8(2/3): 251-269. https://doi.org/10.1515/applirev-2016-1038.

Schmitz, R. M. and Kazyak, E. (2016). Masculinities in cyberspace: an analysis of portrayals of manhood in men's rights activist websites. Social Sciences 5(2) (Online). Available from: https://doi.org/10.3390/socsci5020018.

Schuurmans, J., \& Monaghan, L. (2015). The Casanova-myth: Legend and anxiety in the seduction community. Sociological Research Online 20(1) (Online). Available from: https://doi.org/10.5153/sro.3535.

Scott, M. (2016a) WordSmith Tools version 7. Stroud: Lexical Analysis Software.

Scott, M. (2016b) WordSmith Tools Manual. Stroud: Lexical Analysis Software. Available from: https://lexically.net/downloads/version7/HTML/index.html

Scully, D. and Marolla, J. (1984). Convicted rapists' vocabulary of motive: excuses and justifications. Social Problems 31(5): 530-544.

Shotland, R. L. and Hunter, B. A. (1995). Women's "token resistance" and compliant sexual behaviors are related to uncertain sexual intentions and rape. Personality and Social Psychology Bulletin 21(3): 226-236.

Sillence, E. (2010). Seeking out very like-minded others: exploring trust and advice issues in an online health support group. International Journal of Web Based Communities. 6(4): 376-394. http://dx.doi.org/10.1504/IJWBC.2010.035840. 
Tiersma, P. M. (2007). The language of consent in rape law. In: J. Cotterill (ed.), The Language of Sexual Crime. Basingstoke: Palgrave, pp. 83-103.

Travis, A. (2014). Julien Blanc barred from entering UK. The Guardian. (Online). 19 November 2014. [Accessed May 2018]. Available from:

https://www.theguardian.com/lifeandstyle/2014/nov/19/julien-blanc-barred-enteringuk-pick-up-artist

Urban Dictionary. (2018). 'LMR'. https://www.urbandictionary.com/define.php?term=LMR. 